\title{
The Electrical Performance of Thermoplastic Polymers When Used As Insulation in Cables
}

\author{
Weijia Zhao \\ University of Strathclyde UK \\ weijia.zhao@strath.ac.uk
}

\author{
Wah Hoon Siew \\ University of Strathclyde UK \\ wh.siew@strath.ac.uk
}

\author{
Martin J Given \\ University of Strathclyde UK \\ m.given@strath.ac.uk
}

\begin{abstract}
With the technological development of the chemical synthesis industry, polymeric insulation, especially extruded material, gradually replaces traditional paper-insulated lead covered (PILC) cable to become a popular type of cable. Among potential candidates, XLPE has become a popular material because of its excellent electrical properties as well as dielectric properties. However, the material does not lend itself to ease of recycling. Recently, there is interest shown in using material that is easily recycled. Thermoplastic material seems an automatic contender but research is required to understand the electrical performance of such material. This paper will introduce the advantages of thermosetting material XLPE used as cable insulation and the categories of thermoplastics under different stresses. Thermal stress, voltage stress and environmental stress are the most common stresses considered for material performance. In addition, the degradation mechanisms and the relationship between different stresses were also considered in the paper.
\end{abstract}

Index Terms - Insulation materials, thermoplastic material, insulation degradation mechanism, XLPE, electrical properties, experimental test methods

\section{INTRODUCTION}

Underground cable usage dates back to the time when telegraph was put into use. During that time, many commercial devices to transmit signals became popular and that led to the extensive underground power system in operation around the world today [1]

Underground cables play an important role in power system. With the continuous development of cable qualities, the performance of cable insulation materials has undergone much improvement.

In power systems, voltage ranges of three-phase cables can be divided into several categories. The requirements for cable insulation vary with voltage levels. It is clear that there are four voltage levels in power system, that is, low voltage (below $1 \mathrm{kV}$ ), medium voltage (between $1 \mathrm{kV}$ and $45 \mathrm{kV}$ ), high voltage (between $45 \mathrm{kV}$ and $150 \mathrm{kV}$ ), extra high voltage (more than $150 \mathrm{kV}$ ) [2]. The higher the voltage level is, the more complicated the cable structure is and the higher the requirement of cable insulation.

Initially, paper-insulated lead covered (PILC) cable is the main type of underground cable used in the world prior to the year 1968 for high and medium voltage levels. PILC cable is reliable and has a long service history. However, PILC cable is heavy and it is replaced by polymeric cables gradually, among which, extruded material played an important role. Compared with PILC, extruded cable manufacturing process will reduce defects in cable structure and that improves the aging process. Consequently, extruded insulation material became the new favourite type of cable used by industry due to its light weight and low total cost. The most common extruded materials are polyethylene and cross linked polyethylene.

With the technological development of the chemical synthesis industry, polymeric insulation and insulation based on rubber composites are mainly used in low-voltage power cables. Where possible, the technology is further developed for use in high-voltage power cables [3]. Although polymer degradation is fairly well understood, there are still research interests in the accelerated growth of water trees in polymer under various stress conditions [4]. Water tree grows when voltage stress and moisture exist in the system at the same time and will be accelerated when contaminants exist as well [5].

The role of insulation material is to provide enough protection for both conductor as well as the nearest shielding layer. To provide for the conductor, it is important to protect the conductor from acid, water and other environmental factors. To provide for the nearest shielding layer, it is important to protect that from the voltage stress from the conductor.

The most popular insulation material used for underground cable around the world is cross linked polyethylene (XLPE) with its excellent electrical and physical properties. Although XLPE insulated underground cable occupies a large percentage around the world, it is a thermosetting material which cannot easily be recycled, thus causing environmental issues and hence, it is necessary to investigate some recyclable materials to replace XLPE. Thermoplastic material is a good example for material recyclability.

Before choosing a material candidate, it is necessary to understand the insulation role in cable structure, properties of different materials and the potential stresses faced by insulators to help to establish the standard to select a insulation material.

\section{EXTRUDED MATERIALS FOR CABLE INSULATION}

The insulation layer is always sandwiched between conductor and the nearest shielding layer or nearest electrical ground, as shown in Fig.1. 


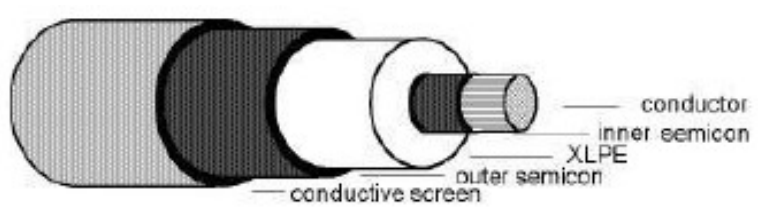

Fig.1 Cable structure [6]

\section{A. Thermosetting materials}

Polymeric materials can be broadly categorised into thermosetting material and thermoplastic materials.

Thermosetting materials can be made from thermoplastic materials, for example, the thermosetting material cross linked polyethylene (XLPE), a typical insulation material, is made from polyethylene, which is a thermoplastic material. Under high pressure and temperature condition and organic peroxide as additive, cross linking structure is produced among individual molecular chains. Therefore, a thermoplastic material changes into a thermosetting material [7], as shown in Fig.2.

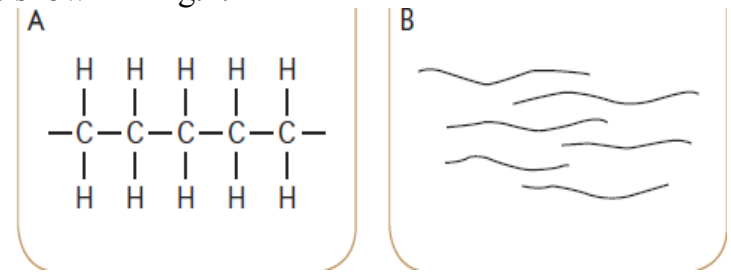

Fig.2 (a) Molecular structure of polyethylene (A and B)
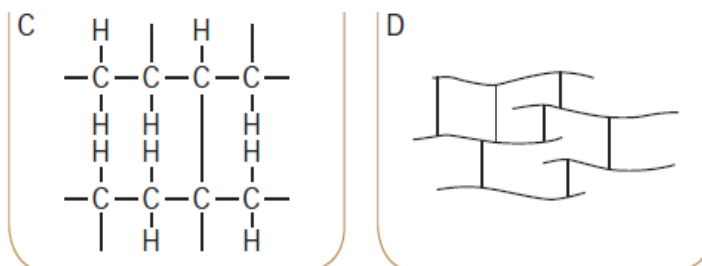

Fig.2 (b) Molecular structure of XLPE (C and D)

With the cross linking structure, XLPE has a much improved dielectric property on the existing excellent electrical properties of polyethylene.

XLPE is a super insulation material. According to the data from Table I, advantages of XLPE will be summarized as follows:

- Higher temperature endurance, XLPE can operate up to 90 degrees, that is, even under fault condition when higher current flowing through the cable, XLPE cable will have the lower risk to breakdown

- Excellent electrical properties, XLPE has a higher volume resistance, lower dielectric constant under 1 $\mathrm{kHz}$, higher dielectric strength, which means, lower current flowing through cable insulation, less energy dissipation and under the same voltage stress, lower temperature will be encountered by the cable insulation. Therefore, it is not surprising that the material is also used in high voltage applications.

- Higher aging resistance under wide range of temperatures, that is, XLPE will have longer service compared with other material
- Higher resistance to contaminants. This property is especially important for underground cables. In soil, water, acid and so on will affect the performance of cable when they permeate into and affect the performance of the insulation material.

- Higher solvent resistance (resistance to weather, oil, organic chemicals and inorganic chemicals)

The advantages are illustrated clearly from Table I. Table I

Comparison of XLPE and other kinds of cables [8]

\begin{tabular}{|c|c|c|c|c|c|}
\hline \multicolumn{6}{|c|}{ Comparison of XLPE and other kinds of cables [8] } \\
\hline \multicolumn{2}{|c|}{ Properties } & $\begin{array}{c}\text { XLPE } \\
\text { Cable }\end{array}$ & $\begin{array}{c}\text { PE } \\
\text { Cable }\end{array}$ & $\begin{array}{c}\text { EPR } \\
\text { Cable }\end{array}$ & $\begin{array}{c}\text { PVC } \\
\text { Cable }\end{array}$ \\
\hline \multirow{3}{*}{$\begin{array}{c}\text { Rated } \\
\text { temperature } \\
(\text { deg } C)\end{array}$} & Normal & 90 & 70 & 90 & 70 \\
\hline & Overload & 130 & 90 & 130 & 100 \\
\hline & $\begin{array}{c}\text { Short } \\
\text { circuit }\end{array}$ & 250 & 200 & 250 & 160 \\
\hline \multicolumn{2}{|c|}{ Tensile strength $\left(\mathrm{kg} / \mathrm{mm}^{2}\right)$} & 1.9 & 1.4 & 0.95 & $1.0-2.5$ \\
\hline \multicolumn{2}{|c|}{ Elongation (\%) } & $\begin{array}{c}200- \\
350\end{array}$ & $\begin{array}{c}600- \\
650 \\
\end{array}$ & $\begin{array}{c}250- \\
550\end{array}$ & $\begin{array}{c}200- \\
450\end{array}$ \\
\hline \multicolumn{2}{|c|}{$\begin{array}{c}\text { Volume resistivity at } 20 \\
\operatorname{deg} C(\Omega . c m)\end{array}$} & $10^{16}$ & $10^{16}$ & $10^{15}$ & $10^{13}$ \\
\hline \multicolumn{2}{|c|}{ Dielectric constant, $1 \mathrm{KHz}$} & 2.3 & 2.3 & 3 & $4.5-9$ \\
\hline \multicolumn{2}{|c|}{ Dielectic strength $(\mathrm{kv} / \mathrm{mm})$} & 20 & 20 & $15-20$ & $15-20$ \\
\hline
\end{tabular}

However, the disadvantage of thermosetting material comes into prominence in the current environmental climate. Cross linking makes thermosetting material not easily recycled; even under high temperature.

With the increasing focus on recyclability and environment friendly material, thermosetting material will not be preferred and it is therefore desirable to investigate a substitution for XLPE [9]. From the point of view of recyclability, thermoplastic material is a good candidate.

\section{B. Thermoplastic materials}

Thermoplastic materials can be divided into different categories [9]:

1) Crystalline thermoplastics: In a crystalline thermoplastic structure, the molecules are arranged in order. With temperature increasing, molecules will obtain higher energy to break the existing order and the crystalline structure will be turned into an amorphous structure. However, when it is cooling down, the molecular structure may not return to the original. The percentage of crystalline region depends on temperature and how quick the temperature changed. If it is cooled quickly, most of the molecules would have not enough time to respond to the change and the resulting crystalline region would be small. If the temperature changes slowly, most of the crystalline region will be retained. Undoubtedly, a thicker sample will have relatively more crystalline region retained because of non-uniform temperature variation compared with that in a thinner sample.

Crystalline thermoplastics have higher and more clearly defined melting temperatures. Typical materials are polypropylene (PP), polyethylene (PE). 
2) Amorphous thermoplastic material: Properties of amorphous thermoplastic material are quite different from those of crystalline thermoplastic materials. Molecules in amorphous thermoplastic material structure are not arranged in order, and hence, it is harder to mould amorphous material than crystalline material [9]. Examples of amorphous thermoplastic materials are polycarbonate (PC), polymethylmethacrylate (PMMA), polystyrene (PS), polyphenylene oxide (PPO), acrylonitrile butadiene styrene (ABS) [9].

3) Semi-crystalline thermoplastics: Semi-crystalline polymers have the status between crystalline material and amorphous material. Therefore, the numerical value for each property is between the value of the crystalline material and that of the amorphous material. Examples are polyester Polybutylene terephtalate (PBT) and Polyamide (Nylon 6, Nylon 66) [9].

The description of polar or nonpolar material is additionally used to classify materials when considering voltage stresses

4) Polar thermoplastics: The polar plastics do not have a fully covalent bond and there is a slight imbalance in the electronic charge of the molecule. In polar plastics, dipoles are created by an imbalance in the distribution of electrons and in the presence of an electric field the dipoles will attempt to move to align with the field [10]. This will create 'dipole polarization' of the material and because movement of the dipoles is involved there is a time element to the movement. Examples of polar plastics are PMMA, PVC, PA (Nylon), PC and these materials tend to be only moderately good as insulators. For polar polymers, a clearly defined low temperature region does not exist [11]. The temperature dependence curve is shown in Fig.3.

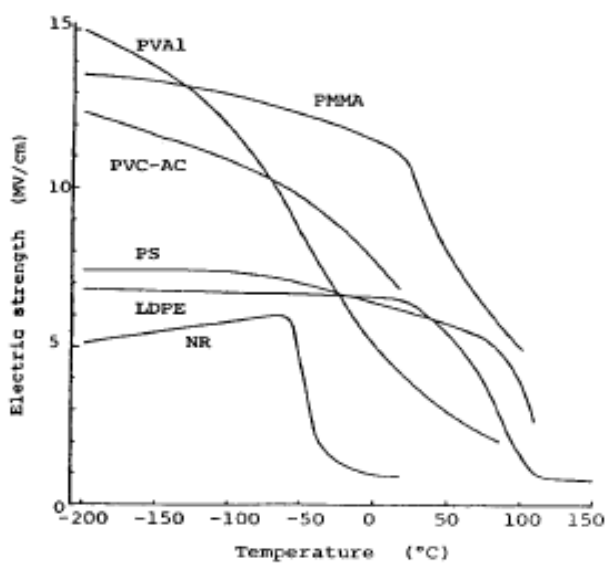

Fig.3 Temperature dependence of polar polymers

5) Nonpolar thermoplastics: The non-polar plastics are truly covalent and generally have symmetrical molecules. In these materials there are no polar dipoles present and the application of an electric field does not try to align any dipoles. The electric field does, however, move the electrons slightly in the direction of the electric field to create 'electron polarization', in this case the only movement is that of electrons and this is effectively instantaneous. Examples of non-polar plastics are PTFE (and many other fluoropolymers), PE, PP and PS and these materials tend to have a high resistivity and a low dielectric constant. The structure of the polymer determines if it is polar or non-polar and this determines many of the dielectric properties of the polymer [10].

For nonpolar polymers, there clearly exist low and high temperature regions for breakdown characteristics [12]. The temperature dependence curve is shown in Fig. 4.

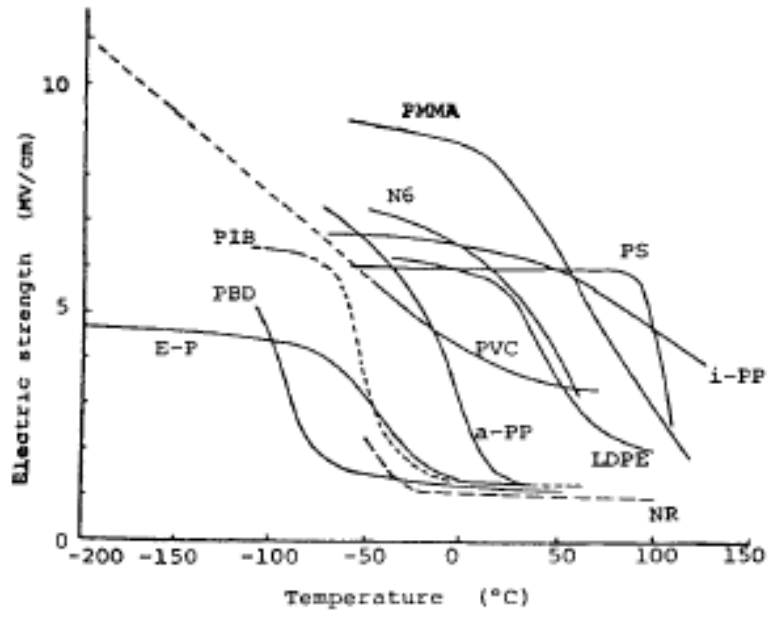

Fig.4 Temperature dependence of nonpolar polymers

\section{IMPORTANT STRESSES FACED BY INSULATION MATERIALS}

Before choosing insulation materials, it is necessary to consider stresses faced by the materials. Stresses can be divided into thermal stresses, electrical stresses and environmental stresses.

Environmental stresses consist of the contaminants from the soil, such as water, acid and so on, which may cause deterioration and which might lead to breakdown of the cable finally. Under voltage stresses in the presence of moisture, it may create water trees, thus degrading the polymer dielectric properties.

Electric stress is the main one for cable insulation. Therefore, the basic role of cable insulation is voltage endurance. Cable insulator is sandwiched between conductors and cable jacket, which should demonstrate excellent electrical properties, such as, high breakdown strength, high volume resistance and low dissipation factor.

Inverse-power law and the exponential law are the common manifestations related to electrical degradation, while the Arrhenius model is the usual approach applied for thermal degradation [13].

Some important parameters to be taken into account when selecting an insulation material are lifetime, stability, temperature endurance, moisture endurance, mechanical properties and dielectric properties [14]. 


\section{TYPES OF MEASUREMENTS ENVISAGED}

In selecting potential replacements for XLPE, investigations will have to be made by making various experimental measurements, having assessed the potential candidates based on existing knowledge. The types of measurements are listed below:

1) Breakdown Strength: As the main stress encountered by insulation material, it is an important factor to evaluate whether a material will be suitable to be used as an insulator. Breakdown strength measures the maximum voltage that can be withstood by the material [15].

2) Partial discharge: It is normally viewed as the precursor to complete breakdown of an insulation material. Knowledge of these will provide information to aid the selection of suitable replacement material for XLPE [16].

3) Dissipation factor: A measure of the energy absorbed by an insulation material under voltage stress. The energy will heat and increase the temperature of the cable [17]. Dissipation factor is an important electrical property and it will be considered in this project.

4) Frequency range: the normal frequency range in cable is below $800 \mathrm{~Hz}$ [18]. However, the frequencies $5 \mathrm{kHz}$ and $10 \mathrm{kHz}$ created by converters or invertors in power systems may also appear in the cable systems and hence, the frequencies mentioned will also be considered as potential stresses in the project.

\section{CONCLUSION}

In brief, from the view of selecting thermoplastics to replace XLPE, this paper summarized the advantages of XLPE (a thermosetting material) as cable insulation to provide a benchmark. Intrinsic properties of thermoplastics were also summarised to help identify potential replacements for XLPE. Potential replacements will then be investigated for their suitability by subjecting them to different stresses, including thermal stress, voltage stress and environmental stress. The equations and relationship among stresses were also established.

\section{REFERENCES}

[1] W. A. Thue, Electrical Power Cable Engineering, 3rd ed. Boca Raton, FL: CRC Press, 2012

[2] E. Peschke and R. von Olshausen, Cable systems for high and extra-hih voltage: cable designs and accessories; dimensioning, development and testing. Weinheim; Cambridge: Wiley-VCH, 1999.

[3] I. C. Report, History and Design Parameters of Low- and Intermediate-Pressure Oil-Filled Cable in the Western Hemisphere Operating at $60 \mathrm{kV}$ and Above, Power Apparatus and Systems, IEEE Transactions on, vol. vol.PAS-88, no.5, pp.541,557.

[4] X. Zheng, G. Chen, A. E. Davies, J. Sutton, and G. Swingler, The influence of survival mechanical stress and voltage frequency on electrical tree in XLPE, 2002 Annual Repoxt Conference on Electrical Insulation and Dielectric Phenomena, pp. 955-958, 2002.
[5] T. Morphology, The Influence of Structure on Water Treeing in Crosslinked Polyethylene, vol. 24, no. 6, pp. 1101-1108, 1989.

[6] B. LENNON, P. H. F. MORSHUIS, T. PERSON, and S. SUTTON, PEA ASSESSMENT OF XLPE AND SEMICON COMPOUNDS FOR HVDC APPLICATION: MEASUREMENTS ON PLAOUE AND MINI-CABLES, no. June, 2011.

[7] XLPE Insulated Power Cables

[8] XLPE Insulated Power Cables Up to $1000 \mathrm{~V}$ (IEC 60502-1)

[9] S. Amin and M. Amin, THERMOPLASTIC ELASTOMERIC (TPE) MATERIALS AND THEIR USE IN OUTDOOR ELECTRICAL INSULATION, vol. 29, pp. 15-30, 2011.

[10] Dielectric Properties of Polymers, pp. 1-7, 2005.

[11] Nagao, M.; Kosaki, M.; Mizuno, Y., On temperature dependence of electric strengths of polar polymeric films in low-temperature region, Dielectric Materials, Measurements and Applications, 1992., Sixth International Conference on , vol., no., pp.85,88, 7-10, Sep 1992

[12] M.A. Bagirov, S.A. Abasov, Ya.G. Ragimov, T.F. Abbasov, Temperature-time dependence of the electric strength of polymers and the effect of some factors influencing this dependence, Polymer Science U.S.S.R., Volume 20, Issue 5, 1978, Pages 1252-1259

[13] Simoni, L., A General Approach to the Endurance of Electrical Insulation under Temperature and Voltage, Electrical Insulation, IEEE Transactions on, vol.EI-16, no.4, pp.277,289, Aug. 1981

[14] W. Shugg, Handbook of electrical and electronic insulating materials, 2nd ed. New York: IEEE Press, 1995.

[15] Grzybowski, S.; McMellon, R. L., Electrical breakdown strength of XLPE cables under combined $A C-D C$ voltage, Southeastcon '95. Visualize the Future., Proceedings., IEEE , vol., no., pp.63,66, 26-29 Mar 1995

[16] Paoletti, G.; Golubev, A., Partial discharge theory and applications to electrical systems, Pulp and Paper, 1999. Industry Technical Conference Record of 1999 Annual, vol., no., pp.124,138, 21-25 June 1999

[17] G. Eklund, Frequency Dependence of the Dissipation Factor of Capacitors up to $10 \mathrm{KHZ}$, pp. 95-96, 2004.

[18] J. Arrillaga, D. A. Bradley, and P. S. Bodger, Power system harmonics, Chichester West Sussex; New York: Wiley, 1985. 